\title{
BMJ Open Readmission and mortality in patients treated by interprofessional student teams at a training ward compared with patients receiving usual care: a retrospective cohort study
}

Karin Hallin, ${ }^{1}$ Max Gordon, ${ }^{1}$ Olof Sköldenberg, ${ }^{1}$ Peter Henriksson, ${ }^{2}$ Anna Kiessling ${ }^{2}$

To cite: Hallin K, Gordon M, Sköldenberg 0, et al. Readmission and mortality in patients treated by interprofessional student teams at a training ward compared with patients receiving usual care: a retrospective cohort study. BMJ Open 2018;8:e022251. doi:10.1136/ bmjopen-2018-022251

- Prepublication history for this paper is available online. To view these files please visit the journal online (http://dx.doi org/10.1136/bmjopen-2018022251).

Received 14 February 2018 Revised 4 July 2018 Accepted 20 September 2018

D Check for updates

(C) Author(s) (or their employer(s)) 2018. Re-use permitted under CC BY-NC. No commercial re-use. See rights and permissions. Published by BMJ.

${ }^{1}$ Division of Orthopaedics, Department of Clinical Sciences, Danderyd Hospital, Karolinska Institutet, Stockholm, Sweden ${ }^{2}$ Division of Cardiovascular Medicine, Department of Clinical Sciences, Danderyd Hospital, Karolinska Institutet, Stockholm, Sweden

Correspondence to Professor Olof Sköldenberg; olof.skoldenberg@gmail.com

\section{ABSTRACT}

Objective This study aimed to compare the rate of patient readmissions and mortality between care provided at an orthopaedic interprofessional training ward (IPTW) and usual care.

Design Retrospective cohort study.

Setting Orthopaedic wards at a level II trauma centre at a Swedish university teaching hospital between 2006 and 2011.

Participants Two cohorts were identified: (1) a control cohort that had not received care at the IPTW, and (2) patients who had been treated for at least 1 day at the IPTW.

Main outcome measures Readmission at 90 days and 1-year mortality.

Results We included 4652 controls and 1109 in the IPTW group. The mean age was 63 years, and $58 \%$ were women. The groups did not differ in any of the outcomes: the readmission rate in the control and IPTW groups was $13.5 \%$ and $14.0 \%$, respectively, while mortality was $5.2 \%$ and $5.3 \%$, respectively. This lack of difference remained after adjusting for confounders.

Conclusion Interprofessional undergraduate training in patient-based settings can be performed in a level II trauma hospital with satisfactory patient safety.

\section{INTRODUCTION}

Current healthcare institutions agree on the importance of collaborative competencies in ensuring patient safety, as outlined in a landmark report from the Institute of Medicine (USA). ${ }^{1}$ However, deficiencies in collaboration remain an important contributor to adverse events in healthcare, ${ }^{2}$ and verbal communication errors between staff members can cause or contribute to a substantial number of severe patient safety incidents. ${ }^{3}$ Hammick et al state in an Association for Medical Education in Europe (AMEE)-guide that learning in interprofessional teams enables practitioners to work better together and improves services. ${ }^{4}$
Strengths and limitations of this study

- This is the first study to compare patient safety between an interprofessional training ward and usual care using robust objective outcome parameters.

- A large sample size from a single centre was collected over a long study period, and an appropriate control group was included.

- Given the study design, that is, an observational cohort study performed in routine care, the comparability of the patient groups cannot be guaranteed.

- Randomisation of patient allocation to the wards was not feasible.

In Sweden, a pioneering effort to improve collaboration between different health education programmes was initiated in $1986 .{ }^{5}$ Over time, this effort developed into what is currently known as interprofessional education (IPE). Most undergraduate health education curricula in Sweden now include mandatory goals regarding interprofessional collaborative competence. IPE enables students from more than one profession to receive training in collaboration and interprofessional communication as early as undergraduate school. The WHO has acknowledged IPE as a necessary step to developing healthcare professionals who are prepared to collaborate in patient management. ${ }^{6}$

In 1996, the first interprofessional training ward (IPTW) worldwide was launched in Sweden. ${ }^{7}$ IPTWs enable IPE to be provided in authentic patient-based settings. IPTWs have been shown to effectively allow students to practise collaborative skills and to develop their professional and interprofessional competencies. $^{8-14}$

Although this form of IPE has been used in healthcare for some time, to our knowledge, 
there have been no studies that have investigated patient safety at IPTWs in terms of patient morbidity and mortality. The existing studies have primarily been based on patients' subjective perceived outcomes. ${ }^{9} 1015$ The Institute of Medicine have performed a comprehensive literature search that revealed very few robust studies designed to evaluate effects of IPE on collaborative behaviour or improvements of patient, population and health system outcomes. ${ }^{16}$ The objective of this study was to assess patient safety at an IPTW by comparing readmission and mortality rates between patients treated by interprofessional student teams at an IPTW and patients treated in usual care without structured interprofessional teamwork.

\section{METHODS}

\section{Study design}

This study used a retrospective cohort design based on registry data.

\section{Setting}

The IPTW of Danderyd Hospital in Stockholm, Sweden, is part of the Department of Orthopaedics. Danderyd Hospital is a level II trauma hospital with a catchment population of 500000 inhabitants. The IPTW at Danderyd Hospital has hosted a 2-week mandatory IPE course at Karolinska Institutet since 1998. Each year, 200-300 undergraduate medical, nursing, physiotherapy and occupational therapy students participate in this course. Students are divided into interprofessional teams and are supported by supervisors. The supervisors were all experienced professionals in their respective field and were also proficient in education. The students' main objectives are to independently provide a high-quality medical, nursing and rehabilitation care to patients and to increase their professional and interprofessional competencies through collaboration. The supervisors remain in the background to facilitate student involvement and to provide a realistic impression of qualified professionals' responsibilities. Thus, the supervisors aim to stay physically away from the patients (while still maintaining in the line-of-sight) as much as possible while doing rounds for instance. Consequently, it is primarily the students who communicate with the patients and who provide the direct patient care. A more detailed description of the design of the IPE course and students' objectives can be found in earlier works. ${ }^{8} 1017$

The IPTW has eight patient beds. Inpatients at the hospital are both acute and elective and are admitted to either the IPTW or to another ward within the department depending on the availability of patient beds. Patients at the IPTW suffer from a variety of orthopaedic diagnoses and present with a wide range of comorbidities, for example, cardiovascular disease, diabetes and malnutrition. Patients with dementia, drug/alcohol abuse or highly demanding medical conditions are not eligible for treatment at the IPTW. In addition to the IPTW, the
Table 1 Inclusion and exclusion criteria

\begin{tabular}{|c|c|}
\hline Inclusion criteria & Exclusion criteria \\
\hline $\begin{array}{l}\text { Inpatient care for } \\
\text { surgery }\end{array}$ & $\begin{array}{l}\text { Treatment provided during vacation } \\
\text { periods* }\end{array}$ \\
\hline \multirow{7}{*}{$\begin{array}{l}\text { Academic period: } \\
01 / 09 / 2006 \text { to } \\
31 / 12 / 2011\end{array}$} & $\begin{array}{l}\text { Hospital stays that were too brief or } \\
\text { too longt }\end{array}$ \\
\hline & Ineligibility for IPTW care due to: \\
\hline & Severe infectious disease $\ddagger$ \\
\hline & Multiple trauma \\
\hline & Other severe conditions \\
\hline & $\begin{array}{l}\text { Drug or alcohol abuse, psychosis, } \\
\text { dementia§ }\end{array}$ \\
\hline & $\begin{array}{l}\text { Paralysis, metastatic disease, HIV/ } \\
\text { AIDS§ }\end{array}$ \\
\hline
\end{tabular}

*Patients treated by routine staff during student vacation periods. †Patients with $\leq 2$ days of stay, as they may have been transfer patients, or those with a length of stay $\geq 2$ weeks, as they were too demanding to be treated by student teams regardless of their registered diagnoses.

$\ddagger$ Patients with International Classification of Diseases (ICD) codes indicating these conditions during their hospital stay, as they were not cared for at the IPTW.

§Patients with ICD codes indicating these comorbidities during their hospital stay or during the previous 2 years.

IPTW, interprofessional training ward.

department of orthopaedics includes three other wards that focus on elective joint replacements, trauma and mixed orthopaedic diagnoses.

\section{Participants}

All patients who received an operation and were cared for during the 1 September 2006 to 31 December 2011 academic semesters were eligible for inclusion. The exclusion criteria aimed to eliminate selection bias by excluding patients treated during students' regular vacation periods and those not eligible to be treated at the IPTW due to severe comorbidities and psychiatric diagnoses (table 1).

For all ICD codes, the corresponding Elixhauser's and Charlson's comorbidity groups were used. ${ }^{18-21}$

\section{Outcome measures}

The primary outcome measure was the 90-day readmission rate. The secondary outcome measure was the 1-year survival rate.

\section{Data sources}

In this registry-based study, information on each patient was obtained through the hospital information system. National Swedish health registers have a $95 \%$ coverage due to their use of personal identity numbers (PINs). We used PINs to retrieve data on all inpatient care documented in the National InPatient Registry (NPR). ${ }^{22}$ The NPR is a valid registry that contains information on the date of admission and discharge, main and secondary diagnoses and procedures. Diagnoses were recorded according to the International Classification of Diseases, 10th version. 
Mortality data were retrieved from the National Board of Health and Welfare of Sweden, extracting deaths and their causes from the Causes of Death Registry.

\section{Exposure}

Exposure was defined as when a patient had been treated by a student team. Patients hospitalised at one of the three regular orthopaedic wards within the department who had $0 \%$ exposure to student teams were therefore included in the control group. Patients hospitalised at the IPTW who were exposed to a student team were included in the 'IPTW' group. The 'IPTW' group was divided into two subgroups according to the proportion of hospital stay in days that the patient had received treatment from a student team. 'Full' referred to patients who had been treated by student teams each day of their hospital stay $(100 \%)$. 'Mixed' referred to patients who had been treated by a student team but not every day of their hospital stay (more than $0 \%$ but less than $100 \%$ of their hospital stay in days). Student teams were not present at the IPTW during the weekends, and this absence affected the proportion of patients' exposure to students. For instance, a patient admitted to the IPTW on Monday who was discharged the following Thursday was exposed to students on all of his/her hospital days (100\%) and was thus included in the 'Full' group. In contrast, a patient admitted on Wednesday who was discharged the following Saturday was exposed to students for 3 out of 4 days, that is, $75 \%$ of his/her hospital stay and was therefore included in the 'Mixed' group.

\section{Confounders}

The confounding variables adjusted for were age, sex, type of care (acute or elective), length of stay and comorbidities. Comorbidities were assessed according to Charlson's Comorbidity Index, a method used to classify comorbid conditions to predict mortality. Each condition was assigned a score depending on the associated risk of mortality for that condition. Scores were summed (0-24) to predict total risk. ${ }^{18}$

\section{Statistical analysis}

The descriptive data for the characteristics of the study population were presented as $\mathrm{n}(\%)$. Continuous variables were presented as the mean and SD. We used Poisson regression with an offset term for person-time (in days) to analyse readmissions within 90 days. Overdispersion in the Poisson regressions was investigated using Cameron and Trivedi's test. ${ }^{23}$ Cox proportional hazards regression was used to conduct the survival analysis. The proportional hazards assumption was tested using Grambsch and Therneau's test. ${ }^{24}$ All analyses were performed using R V.3.2.5, with the rms-package (V.4.5-0) for survival modelling, AER for investigating overdispersion (V.1.2-4), knitr (V.1.12.3) for reproducible research, and Gmisc (V.1.3.1) with Greg (V.1.3.1) for table outputs.

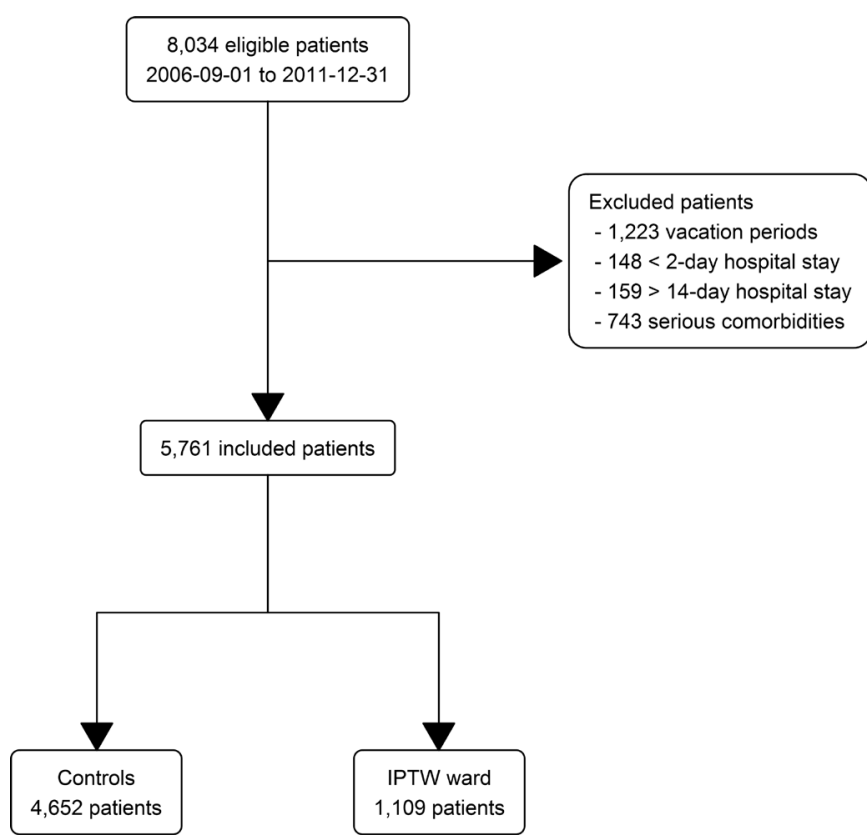

Figure 1 Flow of participants in the study. IPTW, interprofessional training ward.

\section{Patient and public involvement}

The research question and outcome measures were developed to ensure patient safety at the IPTW. No patient organisation or individual patients were involved in the design or conduct of the study but all patients during the study period contributed with anonymised data in the form of registry data to the study. The results from this study will be disseminated to the major patient and teaching organisations in Sweden.

\section{RESULTS}

\section{Patient characteristics}

We identified 8034 eligible patients; of these, 2273 patients were excluded, a majority due to student vacation periods or serious comorbidities (figure 1). Our final cohort consisted of 5761 patients with 6269 admissions: 4652 were controls, and 1109 had been exposed to the IPTW. The mean age at surgery was 63.0 years, and $58 \%$ were women. The median length of stay was 4 days. Table 2 summarises the characteristics of each cohort.

Participants in the IPTW group were on average younger and more frequently treated for acute orthopaedic trauma than the controls. In the IPTW subgroups, patients in the 'Full' group had a shorter length of stay based on the definition of the group, as patients could not be exposed to the IPTW during weekends. Accordingly, those with Full IPTW exposure were younger and healthier than those in the Mixed IPTW group.

\section{Main results}

The 90-day readmission rate did not differ between patients at the IPTW (Full and Mixed exposure groups) and controls (14\% vs $13.5 \%$, respectively). Similarly, there was no difference in 1-year mortality between patients at 
Table 2 Study population characteristics and outcomes

\begin{tabular}{|c|c|c|c|c|}
\hline \multirow[b]{2}{*}{ Variable } & \multirow{2}{*}{$\begin{array}{l}\text { Control group } \\
n=4652\end{array}$} & \multirow{2}{*}{$\begin{array}{l}\begin{array}{l}\text { Interprofessional } \\
\text { training ward (IPTW) }\end{array} \\
\mathrm{n}=1109\end{array}$} & \multicolumn{2}{|c|}{ IPTW subgroups* } \\
\hline & & & $\begin{array}{l}\text { Full } \\
n=418\end{array}$ & $\begin{array}{l}\text { Mixed } \\
n=691\end{array}$ \\
\hline Age & $63.5( \pm 20.0)$ & $61.0( \pm 21.7)$ & $54.9( \pm 20.3)$ & $64.7( \pm 21.7)$ \\
\hline \multicolumn{5}{|l|}{ Sex } \\
\hline Male & $1930(41.5 \%)$ & $468(42.2 \%)$ & $201(48.1 \%)$ & $267(38.6 \%)$ \\
\hline Female & $2722(58.5 \%)$ & $641(57.8 \%)$ & $217(51.9 \%)$ & $424(61.4 \%)$ \\
\hline \multicolumn{5}{|l|}{ Type of care } \\
\hline Acute & 3040 (65.3\%) & $859(77.5 \%)$ & $239(57.2 \%)$ & $620(89.7 \%)$ \\
\hline Elective & $1610(34.6 \%)$ & $248(22.4 \%)$ & $178(42.6 \%)$ & $70(10.1 \%)$ \\
\hline Missing & $2(0.0 \%)$ & $2(0.2 \%)$ & $1(0.2 \%)$ & $1(0.1 \%)$ \\
\hline Length of stay (days) & $4.5( \pm 2.5)$ & $4.4( \pm 2.7)$ & $2.5( \pm 0.8)$ & $5.6( \pm 2.8)$ \\
\hline Charlson's index† & $0.2( \pm 0.7)$ & $0.2( \pm 0.7)$ & $0.2( \pm 0.5)$ & $0.3( \pm 0.8)$ \\
\hline Died during stay & $6(0.1 \%)$ & $1(0.1 \%)$ & $0(0.0 \%)$ & $1(0.1 \%)$ \\
\hline \multicolumn{5}{|l|}{ Readmission at 90 days } \\
\hline No & $4024(86.5 \%)$ & $954(86.0 \%)$ & $380(90.9 \%)$ & $574(83.1 \%)$ \\
\hline Yes & $628(13.5 \%)$ & $155(14.0 \%)$ & $38(9.1 \%)$ & $117(16.9 \%)$ \\
\hline \multicolumn{5}{|l|}{ 1-year mortality } \\
\hline Alive & 4412 (94.8\%) & 1050 (94.7\%) & 410 (98.1\%) & 640 (92.6\%) \\
\hline Dead & $240(5.2 \%)$ & $59(5.3 \%)$ & $8(1.9 \%)$ & $51(7.4 \%)$ \\
\hline
\end{tabular}

Continuous variables are presented as the mean and SD.

*Student exposure denotes the proportion of patients' hospital stay in days that they were exposed to student teams. No exposure denotes patients treated at a usual care ward with no student exposure. Full exposure denotes patients treated at the IPTW with student exposure $100 \%$ of their hospital stay in days. Mixed exposure denotes patients treated at the IPTW with student exposure $>0 \%$ but $<100 \%$ of their hospital stay in days.

†Comorbidity measured according to Charlson's Index. ${ }^{16}$

the IPTW (Full and Mixed groups) and controls (5.3\% vs $5.2 \%$ ).

After adjusting our results for confounders, the 90-day readmission estimates in patients exposed to the student team at the IPTW (in the Full and Mixed groups) varied between 0.89 and 1.03, with an upper CI (representing the worst case scenario) of 1.26 (table 3). For 1-year mortality rates, the estimates of effect size (HR) for the student team-exposed patients at the IPTW ranged between 0.68 and 0.98 , with an upper CI of 1.39 . All mortality rates are presented in table 4 . A forest plot comparing the different outcomes in relation to student exposure, type of care, comorbidity, age, sex and length of stay is shown in figure 2.

\section{DISCUSSION}

In this retrospective cohort study, we found no indication of an elevated risk of 90-day readmission or 1-year mortality in patients treated by supervised interprofessional student teams at the IPTW compared with patients receiving usual care.

Although our research group has previously shown that patients treated by student teams at an IPTW perceived an improved quality of care in terms of collaboration and communication compared with patients treated in usual care, ${ }^{10}$ previous studies have not investigated morbidity and mortality in interprofessional student wards. Hansen et al found no difference in self-reported quality of life between hip and knee arthroplasty patients treated at an interprofessional training unit in Denmark and patients treated at a conventional orthopaedic ward from preoperative inpatient visits to 3 -month postoperative visits. ${ }^{15}$

A 2012 review and meta-analysis of peer-reviewed studies in the English language investigated objective patient outcomes in teaching versus non-teaching general internal medicine settings. No significant differences were found in inpatient mortality, 30-day readmissions or length of stay. ${ }^{25}$ Those results are in line with our study, although the settings differed, as the review did not include patients treated by undergraduate interprofessional student teams.

We found a readmission rate of $14 \%$ within 90 days, and a 1-year mortality of 5\%; these findings are lower than or consistent with the findings of previously published studies on orthopaedic patients in usual care. A readmission rate of $19 \%$ within 3 months was found in patients with hip fracture in the UK. ${ }^{26}$ Our cohort consisted of patients eligible for care at the IPTW and was therefore 
Table 3 Readmission rates at 90 days according to Poisson regression

\begin{tabular}{|c|c|c|c|c|}
\hline & \multicolumn{2}{|c|}{ Crude } & \multicolumn{2}{|c|}{ Adjusted* } \\
\hline & Coef & $\begin{array}{l}2.5 \% \text { to } \\
97.5 \%\end{array}$ & Coef & $\begin{array}{l}2.5 \% \text { to } \\
97.5 \%\end{array}$ \\
\hline \multicolumn{5}{|l|}{ Variable } \\
\hline $\begin{array}{l}\text { Incidence } \\
\text { rate/90 days }\end{array}$ & 0.15 & 0.14 to 0.16 & 0.15 & 0.13 to 0.17 \\
\hline \multicolumn{5}{|l|}{ Student exposure $†$} \\
\hline No $(0 \%)$ & 1.00 & Ref & 1.00 & Ref \\
\hline Full (100\%) & 0.66 & 0.46 to 0.89 & 0.90 & 0.63 to 1.23 \\
\hline $\begin{array}{l}\text { Mixed (>0\% } \\
\text { but }<100 \%)\end{array}$ & 1.29 & 1.05 to 1.56 & 1.04 & 0.85 to 1.27 \\
\hline \multicolumn{5}{|l|}{ Type of care } \\
\hline Acute & 1.00 & Ref & 1.00 & Ref \\
\hline Elective & 0.53 & 0.44 to 0.63 & 0.61 & 0.53 to 0.76 \\
\hline Charlson's Index & 1.65 & 1.55 to 1.74 & 1.43 & 1.28 to 1.46 \\
\hline Age & 1.03 & 1.03 to 1.03 & 1.02 & 1.02 to 1.03 \\
\hline \multicolumn{5}{|l|}{ Sex } \\
\hline Male & 1.00 & Ref & 1.00 & Ref \\
\hline Female & 1.30 & 1.12 to 1.50 & 0.97 & 0.84 to 1.14 \\
\hline Length of stay & 1.12 & 1.10 to 1.15 & 1.02 & 0.99 to 1.05 \\
\hline
\end{tabular}

${ }^{*}$ Confounders adjusted for are type of care, comorbidity, median age, sex and median length of stay.

†Student exposure denotes the proportion of patients' hospital stay in days that they were exposed to student teams. No exposure denotes patients treated at a usual care ward with no student team exposure. Full exposure denotes patients treated at the IPTW with student exposure $100 \%$ of their hospital stay in days. Mixed exposure denotes patients treated at the IPTW with student exposure $>0 \%$ but $<100 \%$ of their hospital stay in days. $\ddagger$ Comorbidity assessed according to Charlson's Index. ${ }^{16}$

COEF, coefficiency; IPTW, interprofessional training ward.

slightly healthier than the patients with orthopaedic fracture in general and cohorts previously reported from our institution. ${ }^{27} 28$

As shown in table 2, patients treated full-time by student teams at the IPTW tended to present a shorter length of stay, required less acute care and had better outcomes than patients in the other two groups. This finding can be explained by the fact that patients in the 'Full' group stayed in the hospital for a maximum of 5 days and were not hospitalised during the weekends, when students were not present. Consequently, patients in need of a longer length of stay or who were hospitalised during weekends were allocated to one of the other two groups. We did adjust for this difference in our analysis, as shown in tables 3 and 4, and found that neither 90-day readmission nor 1-year mortality differed between patients treated at the IPTW (regardless of student exposure) and patients treated in usual orthopaedic care.

In a Cochrane review of IPE research on patient outcomes, Reeves et al suggested that to improve the IPE evidence base, future IPE studies should comprise
Table 4 HRs for 1-year survival after admission (Cox regression model)

\begin{tabular}{|c|c|c|c|c|}
\hline & \multicolumn{2}{|c|}{ Crude } & \multicolumn{2}{|c|}{ Adjusted $^{*}$} \\
\hline & HR & $\begin{array}{l}2.5 \% \text { to } \\
97.5 \%\end{array}$ & HR & $\begin{array}{l}2.5 \% \text { to } \\
97.5 \%\end{array}$ \\
\hline \multicolumn{5}{|l|}{ Student exposure $\dagger$} \\
\hline None (0\%) & 1.00 & Ref & 1.00 & Ref \\
\hline Full (100\%) & 0.37 & 0.18 to 0.75 & 0.68 & 0.33 to 1.39 \\
\hline $\begin{array}{l}\text { Mixed }(>0 \% \\
\text { but }<100 \%)\end{array}$ & 1.47 & 1.08 to 1.99 & 0.98 & 0.71 to 1.33 \\
\hline \multicolumn{5}{|l|}{ Type of care } \\
\hline Acute & 1.00 & Ref & 1.00 & Ref \\
\hline Elective & 0.19 & 0.13 to 0.29 & 0.36 & 0.24 to 0.56 \\
\hline Charlson’s Index $\ddagger$ & 1.96 & 1.82 to 2.12 & 1.48 & 1.36 to 1.60 \\
\hline Age & 1.11 & 1.10 to 1.13 & 1.10 & 1.09 to 1.12 \\
\hline \multicolumn{5}{|l|}{ Sex } \\
\hline Male & 1.00 & Ref & 1.00 & Ref \\
\hline Female & 1.11 & 0.88 to 1.41 & 0.55 & 0.43 to 0.70 \\
\hline $\begin{array}{l}\text { Length of stay } \\
\text { (days) }\end{array}$ & 1.19 & 1.15 to 1.23 & 0.97 & 0.93 to 1.02 \\
\hline
\end{tabular}

${ }^{*}$ Confounders adjusted for are type of care, comorbidity, age, sex and length of stay. For continuous variables, the reference values were set to 0 .

†Student exposure denotes the proportion of patients' hospital stay in days that they were exposed to student teams. No exposure denotes patients treated at a usual care ward with no student team exposure. Full exposure denotes patients treated at the IPTW with student exposure $100 \%$ of their hospital stay in days. Mixed exposure denotes patients treated at the IPTW with student exposure $>0 \%$ but $<100 \%$ of their hospital stay in days. $\ddagger$ Comorbidities measured according to Charlson's Index. ${ }^{16}$ IPTW, interprofessional training ward.

randomised controlled studies with rigorous randomisation and allocation procedures, larger sample sizes, more appropriate control groups and more explicit focuses. ${ }^{29}$ We believe that as randomised studies with and without active student exposure would require very complicated designs, they would not be feasible in routine acute care settings. One type of trial, the cluster randomised controlled trial, where whole wards on hospitals are randomised as IPTW or controls, are possibly feasible. However, the pragmatic study reported here has a clearly described allocation procedure, a large sample size, an appropriate control group and a clear focus. In 2015, Reeves et aldid a follow-up review on IPE effects on patient outcomes and concluded that there was still a need for more studies. ${ }^{16}$ We hope that this study will contribute to the limited, but growing, evidence that IPE can help enhance collaborative practice and improve patient care.

\section{Strengths and limitations}

Given the study design, that is, an observational cohort study performed in routine care, the comparability of the patient groups cannot be guaranteed, that is, that the baseline characteristics of the patient groups are similar. Both 
90-day readmissions (RR) One-year mortality (HR)

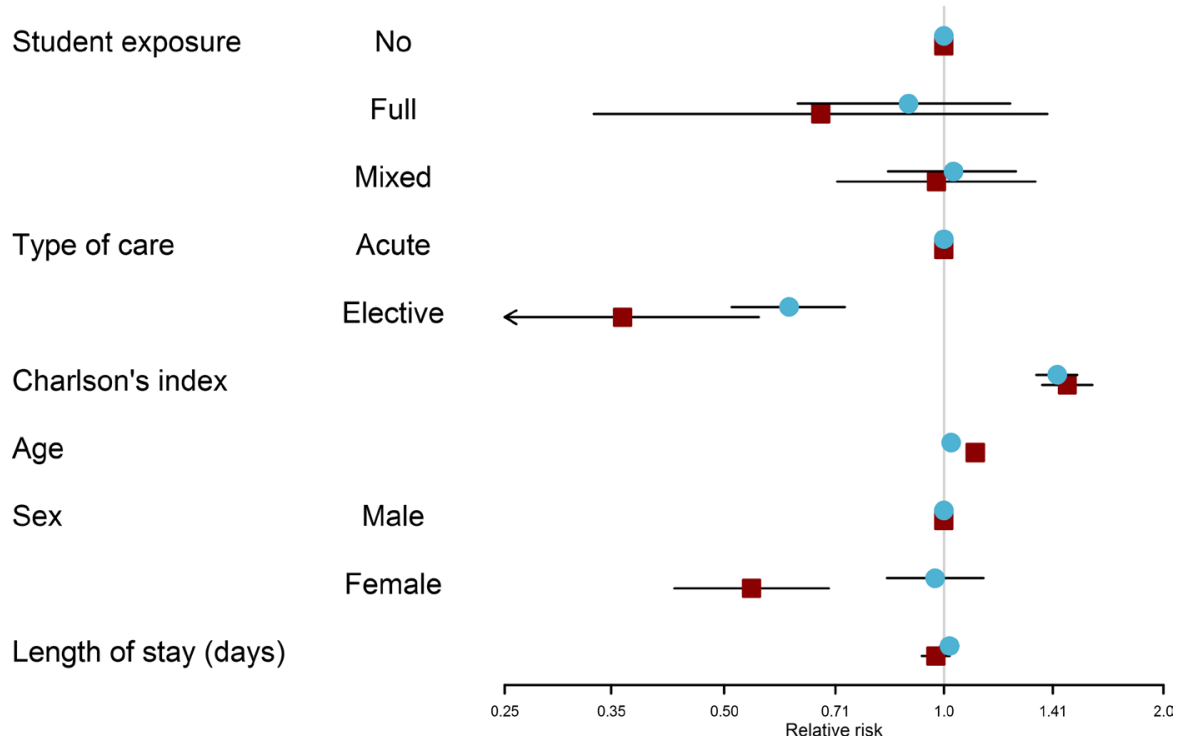

Figure 2 A forest plot comparing the relative risk of 90-day readmission and 1-year mortality in relation to student exposure, type of care, comorbidity, age, sex and length of stay. Student exposure denotes the proportion of patients' hospital stay in days that they were exposed to student teams. No exposure denotes patients treated at a usual care ward with no student team exposure. Full exposure denotes patients treated at the IPTW with student exposure $100 \%$ of their hospital stay in days. Mixed exposure denotes patients treated at the IPTW with student exposure $>0 \%$ but $<100 \%$ of their hospital stay in days. Comorbidities were measured according to Charlson's Index. ${ }^{16}$ For age, the reference values were set to 0 . IPTW, interprofessional training ward; $R R$, relative risk.

acute and elective patients were admitted depending on the availability of patient beds and profiles of the wards. Randomisation of patient allocation to the wards was not feasible. However, as described in the Methods section, our inclusion and exclusion criteria aimed to ensure that the two cohorts were as comparable as possible.

Furthermore, a review of hospital case records could have resulted in more detailed patient information. However, the information in these records has a high grade of uncertainty, and providers in the IPTW could be expected to document more information than those in usual care. It was not possible to account in the model for any difference in care during the 6years of study. However, there were no changes in recommended care or in length of in-hospital stay over the years.

Despite these limitations, we believe that this study has several strengths. To our knowledge, this is the first study to assess patient safety at an IPTW based on robust objective patient outcome data. Furthermore, a large sample size from a single centre was collected over a long study period, and an appropriate control group was included. One could certainly have asked for an even larger cohort of IPTW patients to attain the statistical power needed to formally demonstrate the non-inferiority of the IPTW compared with usual care.

\section{CONCLUSION}

We found no indication of an increased risk of readmission or mortality in patients treated by supervised student teams at an IPTW compared with patients receiving usual care in an orthopaedic ward without structured interprofessional team work. Based on our results, we conclude that undergraduate-level interprofessional training in a patient-based setting within a level II trauma hospital can be performed with satisfactory patient safety.

Acknowledgements We would like to extend our gratitude to all the personnel and students at the IPTW at Danderyd Hospital.

Contributors KH: former director at the IPTW, conceived the original study, wrote the manuscript. MG: supervisor at the IPTW, conceived the original study, performed the statistical analysis and wrote the manuscript. OS: former director at the IPTW, conceived the original study, acquisition of the data, wrote the manuscript. PH: interpreted the data and wrote the manuscript. AK: conceived the original study, wrote the manuscript. All above-listed authors have given final approval of the version published. All above-listed authors agree to be accountable for all aspects of the work in ensuring that questions related to the accuracy or integrity of any part of the work are appropriately investigated and resolved. The authors alone are responsible for the content and writing of the paper.

Funding Financial support was provided through the regional agreement on medical education and clinical research (ALF) between Stockholm County Council and Karolinska Institutet, Sweden.

Competing interests None declared.

Patient consent Not required.

Ethics approval The investigation conformed to the principles outlined in the 'Declaration of Helsinki; 1964' and was approved by the Regional Ethical Review Board in Stockholm, Sweden, D-nr 2013/2000-31/2.

Provenance and peer review Not commissioned; externally peer reviewed.

Data sharing statement The full dataset with statistical code is available on request from the corresponding author. There are no additional unpublished data from the study available.

Open access This is an open access article distributed in accordance with the Creative Commons Attribution Non Commercial (CC BY-NC 4.0) license, which permits others to distribute, remix, adapt, build upon this work non-commercially, 
and license their derivative works on different terms, provided the original work is properly cited, appropriate credit is given, any changes made indicated, and the use is non-commercial. See: http://creativecommons.org/licenses/by-nc/4.0/.

\section{REFERENCES}

1. Institute of Medicine. Crossing the Quality Chasm: a New Health System for the 21st Century. Washington, D.C.: National Academies Press, 2001.

2. Shekelle PG, Wachter RM, Pronovost PJ, et al. Making health care safer II: an updated critical analysis of the evidence for patient safety practices. Evid Rep Technol Assess 2013;2013:1-945.

3. Rabøl LI, Andersen ML, Østergaard D, et al. Descriptions of verbal communication errors between staff. An analysis of 84 root cause analysis-reports from Danish hospitals. BMJ Qual Saf 2011;20:268-74.

4. Hammick M, Olckers L, Campion-Smith C. Learning in interprofessional teams: AMEE Guide no 38. Med Teach 2009;31:1-12.

5. Areskog $\mathrm{NH}$. The need for multiprofessional health education in undergraduate studies. Med Educ 1988;22:251-2.

6. Gilbert JH, Yan J, Hoffman SJ. A WHO report: framework for action on interprofessional education and collaborative practice. J Allied Health 2010;39(Suppl 1):196-7.

7. Wahlström O, Sandén I, Hammar M. Multiprofessional education in the medical curriculum. Med Educ 1997;31:425-9.

8. Hallin K, Kiessling A. A safe place with space for learning: Experiences from an interprofessional training ward. J Interprof Care 2016;30:141-8.

9. Brewer ML, Stewart-Wynne EG. An Australian hospital-based student training ward delivering safe, client-centred care while developing students' interprofessional practice capabilities. J Interprof Care 2013;27:482-8.

10. Hallin K, Henriksson P, Dalén N, et al. Effects of interprofessional education on patient perceived quality of care. Med Teach 2011;33:e22-e26.

11. Jacobsen F, Fink AM, Marcussen V, et al. Interprofessional undergraduate clinical learning: results from a three year project in a Danish Interprofessional Training Unit. J Interprof Care 2009;23:30-40.

12. Wilhelmsson M, Pelling S, Ludvigsson J, et al. Twenty years experiences of interprofessional education in Linkoping-groundbreaking and sustainable. J Interprof Care 2009;23:121-33.

13. Ponzer S, Hylin U, Kusoffsky A, et al. Interprofessional training in the context of clinical practice: goals and students' perceptions on clinical education wards. Med Educ 2004;38:727-36.

14. Reeves S, Freeth D. The London training ward: an innovative interprofessional learning initiative. J Interprof Care 2002;16:41-52.
15. Hansen TB, Jacobsen F, Larsen K. Cost effective interprofessional training: an evaluation of a training unit in Denmark. J Interprof Care 2009;23:234-41.

16. Committee on Measuring the Impact of Interprofessional Education on Collaborative Practice and Patient Outcomes, Board on Global Health, Institute of Medicine. Measuring the Impact of Interprofessional Education on Collaborative Practice and Patient Outcomes. Washington (DC): National Academies Press (US), 2015.

17. Hallin K, Kiessling A, Waldner A, et al. Active interprofessional education in a patient based setting increases perceived collaborative and professional competence. Med Teach 2009;31:151-7

18. Quan H, Li B, Couris CM, et al. Updating and validating the Charlson comorbidity index and score for risk adjustment in hospital discharge abstracts using data from 6 countries. Am J Epidemiol 2011;173:676-82.

19. Sundararajan V, Quan $\mathrm{H}$, Halfon $\mathrm{P}$, et al. Cross-national comparative performance of three versions of the ICD-10 Charlson index. Med Care 2007:45:1210-5

20. Quan H, Sundararajan V, Halfon P, et al. Coding algorithms for defining comorbidities in ICD-9-CM and ICD-10 administrative data. Med Care 2005;43:1130-9.

21. Charlson ME, Pompei P, Ales KL, et al. A new method of classifying prognostic comorbidity in longitudinal studies: development and validation. J Chronic Dis 1987;40:373-83.

22. Ludvigsson JF, Andersson E, Ekbom A, et al. External review and validation of the Swedish national inpatient register. BMC Public Health 2011;11:450

23. Cameron AC, Trivedi PK. Regression-based tests for overdispersion in the Poisson model. J Econom 1990;46:347-64.

24. GRAMBSCH PM, THERNEAU TM. Proportional hazards tests and diagnostics based on weighted residuals. Biometrika 1994;81:515-26.

25. Au AG, Padwal RS, Majumdar SR, et al. Patient outcomes in teaching versus nonteaching general internal medicine services: a systematic review and meta-analysis. Acad Med 2014;89:517-23.

26. Hahnel J, Burdekin H, Anand S. Re-admissions following hip fracture surgery. Ann R Coll Surg Engl 2009;91:591-5.

27. Eriksson M, Kelly-Pettersson P, Stark A, et al. 'Straight to bed' for hip-fracture patients: a prospective observational cohort study of two fast-track systems in 415 hips. Injury 2012;43:2126-31.

28. Gordon M, Berntsson PO, Sjölund E, et al. Loss of offset after pertrochanteric hip fractures affects hip function one year after surgery with a short intramedullary nail. A prospective cohort study. Int Orthop 2016;40:799-806.

29. Reeves S, Zwarenstein M, Goldman J, et al. Interprofessional education: effects on professional practice and health care outcomes. Cochrane Database Syst Rev 2008:CD002213. 